\title{
Iron Requirement in the Bactericidal Mechanism of Streptonigrin
}

\author{
HEATHER N. YEOWELL* AND JAMES R. WHITE \\ Department of Biochemistry and Nutrition, University of North Carolina at Chapel Hill, Chapel Hill, North \\ Carolina 27514
}

Received 19 July 1982/Accepted 30 September 1982

\begin{abstract}
Mutants of Escherichia coli K-12 that are unable to make use of the enterochelin transport system were used to confirm that streptonigrin requires iron for its bactericidal action. Correlation of viability studies and ${ }^{55} \mathrm{Fe}^{3+}$ uptake experiments showed that killing by streptonigrin increased with an increase in ${ }^{55} \mathrm{Fe}^{3+}$ uptake by the cells. Streptonigrin did not kill iron-starved mutants that were unable to import iron. The level of iron uptake by these mutants was manipulated by agents such as (i) the enterochelin biosynthetic precursors 2,3-dihydroxybenzoic acid ( 2 $\left.\times 10^{-5} \mathrm{M}\right)$ and shikimic acid $\left(2 \times 10^{-4} \mathrm{M}\right)$, (ii) citrate $\left(10^{-2} \mathrm{M}\right)$, which promotes iron uptake by an independent pathway, and (iii) the chelating agents desferrioxamine $\left(2 \times 10^{-4} \mathrm{M}\right)$ and orthophenanthroline $\left(10^{-4} \mathrm{M}\right)$. Addition of the precursors shikimate and dihydroxybenzoate to strain AB2847 (aroB) and dihydroxybenzoate to strain AN193 (entA), allowing these strains to make enterochelin, resulted in an increase in $\mathrm{Fe}^{3+}$ uptake and a corresponding sharp increase in killing by streptonigrin. Addition of enterochelin itself $\left(10^{-6} \mathrm{M}\right)$ caused an even more pronounced effect. Studies on the effect of citrate in strain AN102 (fep) showed that this mutant was not killed by streptonigrin $\left(4 \times 10^{-5} \mathrm{M}\right)$, even in the presence of citrate; however, overnight growth in citrate induced $\mathrm{Fe}^{3+}$ uptake by means of the ferric citrate transport system and resulted in killing by streptonigrin. These studies showed a clear correlation between the change in levels of intracellular iron and the bactericidal effectiveness of streptonigrin.
\end{abstract}

Streptonigrin is an aminoquinone antitumor agent that causes DNA degradation in Escherichia coli. It requires both intracellular reduction and the presence of oxygen for its bactericidal effect $(6,17)$. Streptonigrin toxicity is dependent on a favorable oxidation-reduction state (5). Its mechanism of action appears to involve a cyclic reduction and oxidation process producing a reactive oxygen species which damages DNA (2; J. R. White, T. O. Vaughan, and W.-S. Yeh, Proc. Fed. Am. Soc. Exp. Biol. 30:1145, 1971). Previous experiments have shown an enhancement of streptonigrin killing in the presence of certain heavy metal divalent cations such as $\mathrm{Zn}^{2+}, \mathrm{Co}^{2+}$, and $\mathrm{Mn}^{2+}$ (18). These metals form complexes with streptonigrin and promote binding of the antibiotic to DNA in vitro; whether this is a crucial part of the mechanism of action of streptonigrin remains to be clarified. More recently, we have provided evidence that iron plays an important role in the bactericidal action of streptonigrin (19).

In the work reported here we used iron transport mutants of $E$. coli $\mathrm{K}-12$ to demonstrate that as the levels of iron uptake by the cells were altered, so the killing by streptonigrin was corre- spondingly altered. At neutral $\mathrm{pH}$, iron occurs as a highly insoluble ferric hydroxide polymer, which often makes it a growth-limiting factor for bacteria. Under iron-deficient conditions, $E$. coli synthesizes and excretes a siderophore, enterochelin, to chelate the required iron; this is transported back into the cell as a ferrienterochelin complex (14). Citrate can also promote iron uptake. It does so by inducing a ferric citrate transport system, which allows iron into the cells (4). Unlike enterochelin, citrate itself does not enter the cells. A low-affinity iron uptake system is also present which can be suppressed by the addition of chelating agents such as nitrilotriacetic acid (NTA; 4).

Mutants of the iron transport system that we have studied in detail include the following strains: (i) AB2847 (aroB), which lacks dehydroquinate synthetase and is unable to synthesize enterochelin unless supplied with a precursor such as dihydroxybenzoate (DHB) or shikimate; (ii) AN193 (entA), which lacks 2,3-dihydro-2,3dihydroxybenzoate dehydrogenase and is unable to make enterochelin unless supplied with DHB; and (iii) AN102 ( $f e p$ ), which can synthesize enterochelin but is defective in transporting 
TABLE 1. E. coli strains used

\begin{tabular}{|c|c|c|}
\hline Strain & Chromosomal markers $^{a}$ & Comment \\
\hline 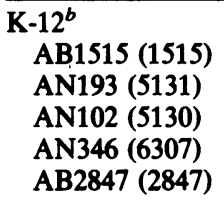 & $\begin{array}{l}\text { thi trp purE proC leuB tonA } \\
\text { thi trp entA } 403 \text { proC leuB tonA } \\
\text { thi trp fep proC leu tonA } \\
\text { entA } 403 \text { pyrE ilv argH } \\
\text { aroB malT }\end{array}$ & $\begin{array}{l}\text { Other strain designation: } 13-6, \text { N. Schwartz strain } \\
\text { Derived from AB1515 } \\
\text { Derived from AB1515 } \\
\text { F. Gibson strain } \\
\text { A. J. Pittard strain }\end{array}$ \\
\hline
\end{tabular}

a The gene symbols follow those of Bachmann and Low (1).

b These strains were obtained from the Coli Genetic Stock Center, Yale University School of Medicine, New Haven, Conn. Parentheses give CGSC number.

c Strain AB2847 is a phage T6-resistant, phage $\lambda$-resistant derivative of strain 10-1 of $R$. Somerville, grown in M9 medium containing phenylalanine, tyrosine, and tryptophan plus $2 \times 10^{-6} \mathrm{M}$ shikimate.

it into the cells. Viability studies on these strains were carried out during incubation with streptonigrin under various conditions of iron uptake. The level of iron was manipulated by initiating enterochelin synthesis by supplying the necessary precursors (in the case of strain AB2847 or AN193) or by inducing the ferric citrate transport system (in the case of strain AN102). The bactericidal action of streptonigrin was shown to correlate closely with the level of iron uptake.

\section{MATERIALS AND METHODS}

Chemicals. Streptonigrin was supplied by the Drug Synthesis and Chemistry Branch, Division of Cancer Treatment, National Cancer Institute. A stock solution $\left(500 \mu \mathrm{g} / \mathrm{ml}, 10^{-3} \mathrm{M}\right)$ was prepared by dissolving streptonigrin in Tris-hydrochloride buffer ( $\mathrm{pH} 7.8)$. It was stored at $4^{\circ} \mathrm{C}$ in the dark. Other chemicals were supplied as follows: desferrioxamine from Ciba-Geigy; ${ }^{55} \mathrm{FeCl}_{3}(14.7 \mathrm{Ci} / \mathrm{g})$ from New England Nuclear Corp.; 2,3-DHB, shikimic acid, and orthophenanthroline (1,10-phenanthroline) from Aldrich Chemical Co.; 8hydroxyquinoline, chloramphenicol, and NTA from Fisher Scientific Co.

Bacterial strains and growth conditions. $E$. coli strains (Table 1) were maintained and stored at $4^{\circ} \mathrm{C}$ on nutrient agar slants. M9 medium (11) was extracted overnight with 8-hydroxyquinoline to remove $\mathrm{Fe}^{3+}$ (9). The concentration of iron in the extracted M9 (less than $\left.10^{-7} \mathrm{M}\right)$ was determined by a bathophenanthroline assay as described previously $(13,19)$. Unless otherwise stated, cells were grown overnight in extracted M9 medium with the addition of $2 \times 10^{-6} \mathrm{M}$ $\mathrm{Fe}^{3+}$ and $2 \mathrm{mg}$ of glucose per $\mathrm{ml}$ and, where required, other growth factors, including L-tryptophan $\left(2 \times 10^{-4}\right.$ $\mathrm{M})$, adenine $\left(1.5 \times 10^{-4} \mathrm{M}\right)$, thiamine $\left(10^{-6} \mathrm{M}\right)$, Lleucine $\left(3 \times 10^{-4} \mathrm{M}\right)$, L-proline $\left(10^{-3} \mathrm{M}\right)$, L-phenylalanine $\left(2 \times 10^{-4} \mathrm{M}\right)$, L-tyrosine $\left(2 \times 10^{-4} \mathrm{M}\right)$, shikimic acid $\left(2 \times 10^{-6} \mathrm{M}\right)$, and sodium citrate $\left(10^{-2} \mathrm{M}\right)$.

Viability studies. Experiments were carried out on aerated $\log$-phase cultures at a cell density of $1 \times 10^{8}$ to $2 \times 10^{8}$ cells per $\mathrm{ml}$. Viabilities were determined by serial dilution in saline and plating on nutrient agar (Difco Laboratories).

Iron uptake studies. All of the glassware used in these experiments was soaked overnight in $0.5 \%$
EDTA and washed thoroughly with distilled water and finally deionized water. Membrane filters $(0.45 \mu \mathrm{m}$; Millipore Corp.) were soaked before use for $1 \mathrm{~h}$ in $1 \%$ $\mathrm{NaCl}$ containing $4 \times 10^{-5} \mathrm{M}$ ammonium-Fe ${ }^{3+}$-EDTA complex (16), washed thoroughly with deionized water, and air dried. NTA was always used in these assays to eliminate the low-affinity iron uptake system (4) and to maintain the $\mathrm{Fe}^{3+}$ in solution.

Cells were grown overnight in extracted M9 medium with addition of $2 \times 10^{-6} \mathrm{M} \mathrm{FeCl}_{3}$ and growth factors as required. A sample was diluted into iron-depleted M9 medium and grown for a minimum of three doublings to an optical density at $578 \mathrm{~nm}$ of 0.4 to 0.6 . This corresponds to a cell density of $4 \times 10^{8}$ to $6 \times 10^{8}$ cells per $\mathrm{ml}$. The cells were chilled and harvested by centrifugation; they were washed twice with irondepleted M9 medium and resuspended in iron-depleted M9 medium with added growth requirements to a density of $1.5 \times 10^{9}$ cells per $\mathrm{ml}$. The cell suspension was shaken at $37^{\circ} \mathrm{C}$ for $10 \mathrm{~min}$ before being used in the ${ }^{55} \mathrm{Fe}^{3+}$ studies. ${ }^{55} \mathrm{FeCl}_{3}$ with NTA in iron-depleted M9 medium was shaken for 1 to $2 \mathrm{~h}$ at $37^{\circ} \mathrm{C}$ and membrane filtered before uptake experiments were started. Duplicate samples $(5 \mu \mathrm{l})$ of the ${ }^{55} \mathrm{Fe}$ medium were counted before and after filtering. An equal volume of cell suspension was added to the filtered ${ }^{55} \mathrm{Fe}$ medium at $37^{\circ} \mathrm{C}$, and, at measured time intervals and optical densities, 200- $\mu$ l samples were membrane filtered, washed twice with citrate $(0.1 \mathrm{M})$, and air dried. In experiments with orthophenanthroline, filters were washed twice with $10^{-2} \mathrm{M}$ orthophenanthroline. The filters were counted in $15 \mathrm{ml}$ of toluene scintillation fluid (17) in an LKB (1215 Rack Beta) liquid scintillation counter. A sample containing 6 pmol of ${ }^{55} \mathrm{Fe}$ was dried on filters and used as a standard for converting counts per minute of ${ }^{55} \mathrm{Fe}$ to moles of ${ }^{55} \mathrm{Fe}$.

This assay was carried out with final concentrations of $1.5 \times 10^{-4} \mathrm{M}$ NTA and $0.3 \times 10^{-6} \mathrm{M}^{55} \mathrm{Fe}(0.25 \mu \mathrm{Ci} /$ $\mathrm{ml})$. The ${ }^{55} \mathrm{Fe}-\mathrm{NTA}$ medium contained the following additions, either singly or in combination, as required (final concentration): (i) citrate $\left(10^{-2} \mathrm{M}\right)$; (ii) $\mathrm{DHB}(4 \times$ $\left.10^{-5} \mathrm{M}\right)$; (iii) shikimate $\left(2 \times 10^{-4} \mathrm{M}\right)$; (iv) enterochelin $\left(10^{-6} \mathrm{M}\right)$; (v) desferrioxamine $\left(2 \times 10^{-4} \mathrm{M}\right)$; (vi) orthophenanthroline $\left(10^{-4} \mathrm{M}\right)$; (vii) $\mathrm{KCN}\left(10^{-2} \mathrm{M}\right)$; and (viii) chloramphenicol $(200 \mu \mathrm{g} / \mathrm{ml})$. Blank determinations, in which cell suspension was replaced by uptake medium, were made for each solution, and 

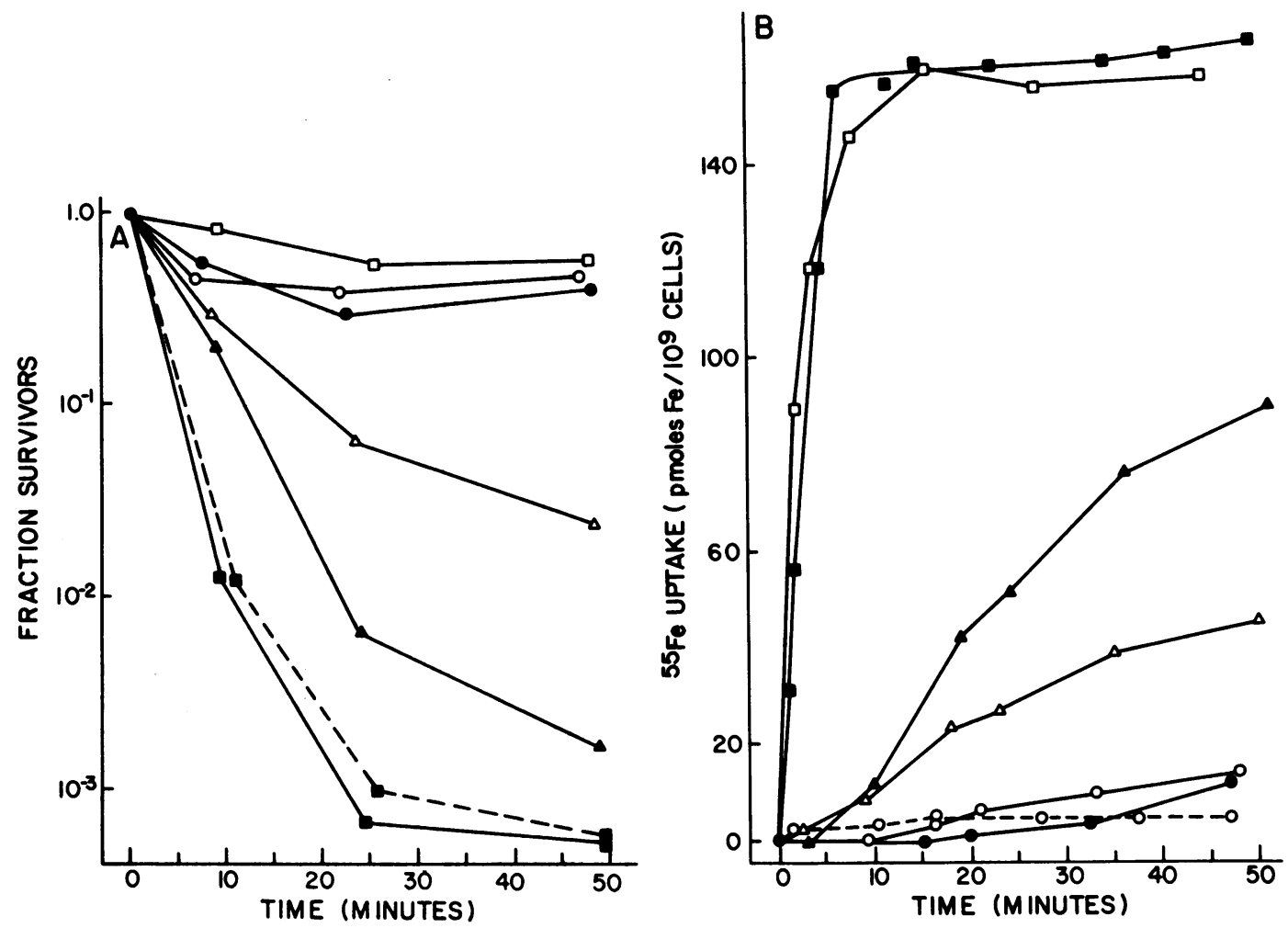

FIG. 1. Effect of enterochelin, shikimate, DHB, citrate, and orthophenanthroline on action of streptonigrin on (A) and uptake of ${ }^{55} \mathrm{Fe}^{3+}$ by (B) strain AB2847 (aroB). (A) All agents were added at 0 min to log-phase cultures of cells growing aerobically in $\mathrm{M} 9$ medium in the presence of $2 \times 10^{-6} \mathrm{M} \mathrm{Fe}^{3+}$ and $1.5 \times 10^{-4} \mathrm{M}$ NTA with added requirements. Concentrations were: streptonigrin, $2.7 \times 10^{-5} \mathrm{M}$; enterochelin, $10^{-6} \mathrm{M}$; shikimate, $2 \times 10^{-4} \mathrm{M}$; $\mathrm{DHB}, 4 \times 10^{-5} \mathrm{M}$; citrate, $10^{-2} \mathrm{M}$; orthophenanthroline, $10^{-4} \mathrm{M}$. All cultures contained streptonigrin and

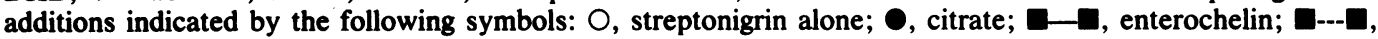
enterochelin plus desferrioxamine; $\square$, enterochelin plus orthophenanthroline; $\Delta$, shikimate; $\triangle$, DHB. (B) Cells were prepared for iron uptake studies as described in the text. Concentrations of agents in uptake medium were as for (A). Symbols: $\bigcirc-O$, no addition; $O$, citrate, $\square$, enterochelin; $\square$, enterochelin plus orthophenanthroline; $\triangle$, shikimate; $\triangle$, DHB; $\bigcirc-. .-O$, strain AB2847 preincubated for 10 min with $10^{-2} \mathrm{M} \mathrm{KCN}$ before the addition of ${ }^{35} \mathrm{Fe}$ and enterochelin.

uptake data were corrected accordingly. Each iron uptake experiment was carried out at least twice. Uptake results were expressed in picomoles of ${ }^{55} \mathrm{Fe}$ per $10^{9}$ cells.

Preparation of enterochelin. Enterochelin was isolated from a 1-liter stationary-phase culture of strain AN102 (fep) in M9 medium with added growth requirements (7).

\section{RESULTS}

Streptonigrin alone was not very effective against strain AB2847, but addition of the enterochelin precursors shikimate or DHB caused an appreciable increase in killing (Fig. 1A). In the presence of enterochelin itself, streptonigrin had an even greater effect. Orthophenanthroline, a powerful chelator of iron and other heavy metals, protected the cells from being killed by streptonigrin with added enterochelin. In con- trast, the iron chelator desferrioxamine had little effect on the action of streptonigrin in the presence of enterochelin. Simultaneous addition of citrate together with streptonigrin caused no enhancement of the bactericidal action of the antibiotic.

Studies of ${ }^{55} \mathrm{Fe}^{3+}$ uptake by strain AB2847 in the presence of enterochelin showed a large uptake of greater than $150 \mathrm{pmol}$ of ${ }^{55} \mathrm{Fe}^{3+}$ per $10^{9}$ cells within 5 min (Fig. 1B). This uptake was not affected by orthophenanthroline. The energy dependence of this ferrienterochelin uptake process (12) was shown by addition of an energy inhibitor such as $\mathrm{KCN}\left(10^{-2} \mathrm{M}\right)$. $\mathrm{NaN}_{3}\left(\mathbf{1 0}^{-2} \mathrm{M}\right)$ (not shown) had a similar effect. These inhibitors completely eliminated any iron uptake by strain AB2847. DHB and shikimate promoted ${ }^{55} \mathrm{Fe}$ uptake by this aroB mutant, but to a lesser extent than did enterochelin. The uptake of ${ }^{55} \mathrm{Fe}$ in the absence of any other agents, or with 

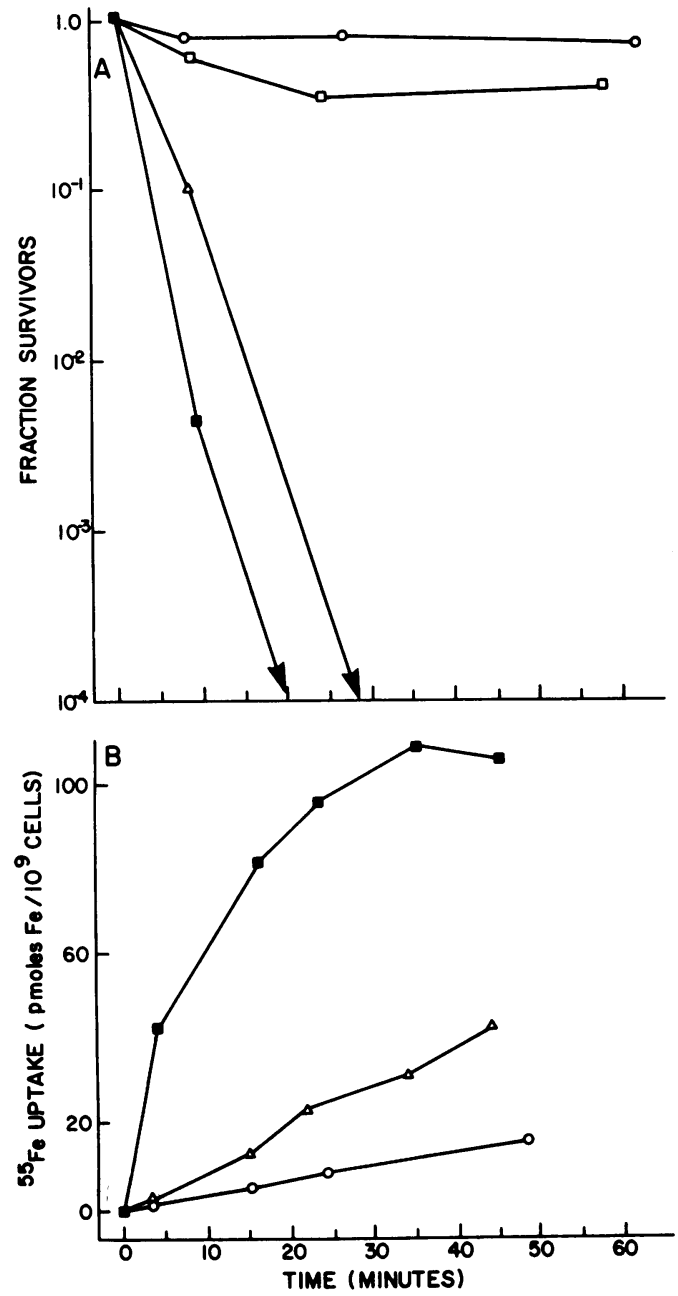

FIG. 2. Effects of enterochelin and DHB on (A) action of streptonigrin on and (B) uptake of ${ }^{55} \mathrm{Fe}^{3+}$ by strain AN193 (entA). (A) All agents were added at 0 min to log-phase cultures of strain AN193 growing aerobically in M9 medium containing $2 \times 10^{-6} \mathrm{M} \mathrm{Fe}^{3+}$ and $1.5 \times 10^{-4} \mathrm{M}$ NTA with added growth factors. Concentrations were: streptonigrin, $4 \times 10^{-5} \mathrm{M}$; enterochelin, $10^{-6} \mathrm{M}$; DHB, $2 \times 10^{-5} \mathrm{M}$; orthophenanthroline, $10^{-4} \mathrm{M}$. All cultures contained streptonigrin and, in addition: $O$, streptonigrin alone; $\mathbf{\square}$, enterochelin; $\triangle$, DHB; $\square$, orthophenanthroline plus enterochelin. (B) Cells were prepared as described in the text for iron uptake studies. Concentrations of agents in uptake medium were as for (A). Symbols: $O$, no additions; $\triangle$, DHB; $\mathbf{a}$, enterochelin.

citrate added simultaneously, was at a very low level.

Strain AN193 (entA) is another mutant unable to make enterochelin unless supplied with a precursor such as DHB. As observed with strain AB2847, the bactericidal action of streptonigrin was strongly enhanced in strain AN193 by the addition of DHB or, to an even greater extent, by enterochelin (Fig. 2A). Orthophenanthroline eliminated the lethal effect of streptonigrin in the presence of enterochelin, as illustrated in Fig. $1 \mathrm{~A}$ for strain AB2847. Results on another entA mutant, strain A346, were similar (not shown). ${ }^{55} \mathrm{Fe}$ uptake studies (Fig. 2B) showed that enhanced iron uptake occurred in strain AN193 in the presence of either DHB or enterochelin.

Strain AN193, in contrast to strain AB2847, showed a fairly rapid response to citrate. Killing by streptonigrin in the presence of citrate was increased over that by streptonigrin alone after about 20 to $30 \mathrm{~min}$ (Fig. 3A). This lag time was eliminated by preincubation of strain AN193 for $60 \mathrm{~min}$ in citrate before streptonigrin addition. To test whether this lag period involved synthesis of new proteins required for citrate-induced iron transport (resulting in enhanced streptonigrin killing), strain AN193 was preincubated for 15 min with chloramphenicol before the addition of citrate and streptonigrin. Although killing was reduced, chloramphenicol did not completely eliminate the citrate effect. Enhancement of the action of streptonigrin by chloramphenicol was observed, as described previously (17). Orthophenanthroline eliminated the lethal action of streptonigrin in the presence of citrate; desferrioxamine, although not quite as effective as orthophenanthroline, greatly reduced the lethality. A similar response to citrate and chloramphenicol was given by strain AN346, another entA mutant.

In the ${ }^{55} \mathrm{Fe}^{3+}$ uptake studies shown in Fig. 3B, addition of citrate sharply increased the uptake of iron after about $20 \mathrm{~min}$. This effect was eliminated by the addition of desferrioxamine. A 60-min preincubation of strain AN193 in citrate, before the addition of ${ }^{55} \mathrm{Fe}$ uptake medium, resulted in a rapid uptake of ${ }^{55} \mathrm{Fe}$. This uptake was sharply reduced if chloramphenicol was added to the citrate-preincubated culture $15 \mathrm{~min}$ before the start of the iron uptake experiment.

Growth of $E$. coli K-12 AN102 (fep) in lowiron medium results in accumulation of ferrienterochelin outside the cell. Overnight cultures of strain AN102 had, as a result, a characteristic pink color. As seen in Fig. 4A, streptonigrin was not very effective against strain AN102. Citrate, when added together with streptonigrin, resulted in even less killing. However, when strain AN102 was grown overnight in citrate $\left(10^{-2} \mathrm{M}\right)$, the bactericidal action of streptonigrin was strongly enhanced when added in the presence of citrate. If streptonigrin was added without citrate, its action was transient. After 50 min, the fraction of surviving cells declined an additional 100 -fold in the presence of citrate. The addition of NTA, which eliminates the lowaffinity iron uptake system (4), had no effect on 

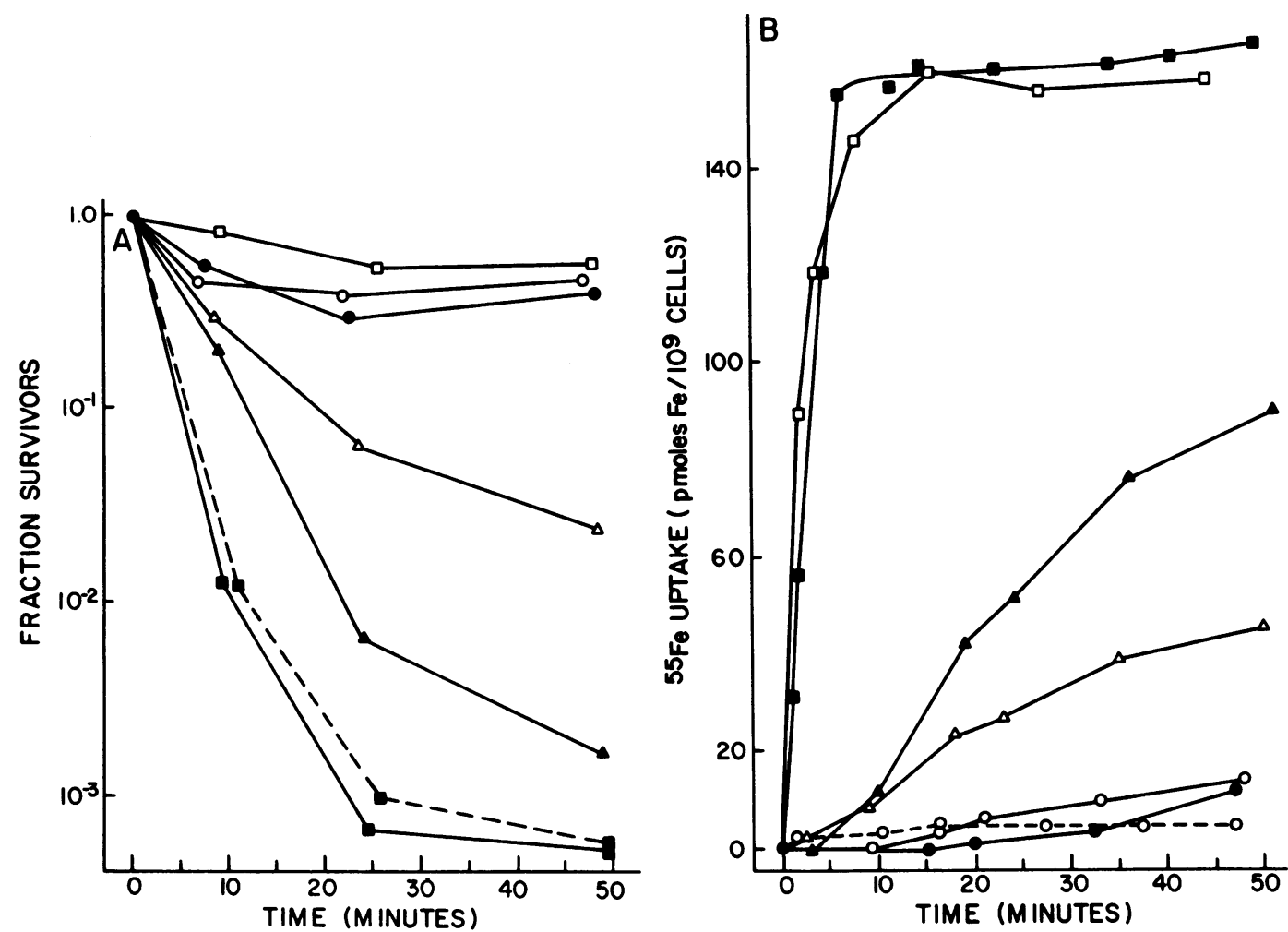

FIG. 3. Effect of either preincubating strain AN193 with citrate for 60 min or simultaneously adding citrate to strain AN193 (in the presence and absence of chloramphenicol) on (A) killing by streptonigrin and (B) uptake of ${ }^{35} \mathrm{Fe}^{3+}$. (A) Unless otherwise stated, all agents were added at 0 min to log-phase cultures growing aerobically in M9 medium containing $2 \times 10^{-6} \mathrm{M} \mathrm{Fe}^{3+}$ and $1.5 \times 10^{-4} \mathrm{M}$ NTA, with added requirements. Concentrations were: streptonigrin, $4 \times 10^{-5} \mathrm{M}$; citrate, $10^{-2} \mathrm{M}$; chloramphenicol, $200 \mu \mathrm{g} / \mathrm{ml}$; orthophenanthroline, $10^{-4} \mathrm{M}$; desferrioxamine, $2 \times 10^{-4} \mathrm{M}$. All cultures contained streptonigrin and, in addition: $O$, streptonigrin alone; $\bigcirc$, citrate; $\square$, citrate plus orthophenanthroline; $\square---. \square$, citrate plus desferrioxamine; $\Delta$, cells preincubated for 60 min with citrate before streptonigrin addition; $\square$, cells preincubated for $15 \mathrm{~min}$ with chloramphenicol before streptonigrin addition; $\Delta$, cells preincubated for $15 \mathrm{~min}$ with chloramphenicol before the addition of streptonigrin plus citrate. (B) Cells were prepared as described in the text for iron uptake studies. Concentrations of agents added to uptake medium were: citrate, $10^{-2} \mathrm{M}$; chloramphenicol, $200 \mu \mathrm{g} / \mathrm{ml}$; desferrioxamine, $2 \times 10^{-4} \mathrm{M}$. Symbols: $O$, no addition; $O$, citrate; $\Delta$, cells preincubated with citrate for 60 min before ${ }^{55} \mathrm{Fe}$ uptake studies; $\triangle$, cells preincubated with citrate for $60 \mathrm{~min}$ and with chloramphenicol for $10 \mathrm{~min}$ before addition of ${ }^{55} \mathrm{Fe}$ medium; $\square---\square$, citrate plus desferrioxamine.

the killing by streptonigrin in the presence of citrate. Cox et al. (3) have shown that strain AN102 has an inducible citrate-dependent iron transport system. The growth rate of strain AN102 increases in the presence of $10^{-2} \mathrm{M}$ citrate, corresponding to a citrate-dependent uptake of iron. Our results, as shown in Fig. 4B, confirmed that uptake of ${ }^{55} \mathrm{Fe}^{3+}$ by strain AN102 grown without citrate was at a very low level, both with and without added citrate. Overnight growth in citrate resulted in a sharply increased ${ }^{35} \mathrm{Fe}$ uptake in the presence of added citrate. This uptake was much less if no citrate was added to the uptake medium. The citrate-induced increase of iron uptake by strain AN102 corresponded closely to the enhancement of the bactericidal action of streptonigrin against this mutant.

$E$. coli W lacks a citrate-inducible iron transport mechanism (20), although it possesses an enterochelin transport system. When $E$. coli W was grown in $\mathbf{M} 9$ medium containing $2 \times 10^{-6} \mathrm{M}$ $\mathrm{Fe}^{3+}$, streptonigrin killed effectively (after 50 min, the fraction viable was $5.1 \times 10^{-5}$ ). This level of killing by streptonigrin was not enhanced by either simultaneous addition of citrate or overnight growth of strain $\mathrm{W}$ in citrate. ${ }^{55} \mathrm{Fe}^{3+}$ uptake studies on $E$. coli $\mathrm{W}$ grown overnight in the presence and absence of citrate showed that addition of citrate did not enhance iron uptake in cells grown either with or without citrate. This is in contrast to strain AN102, in 


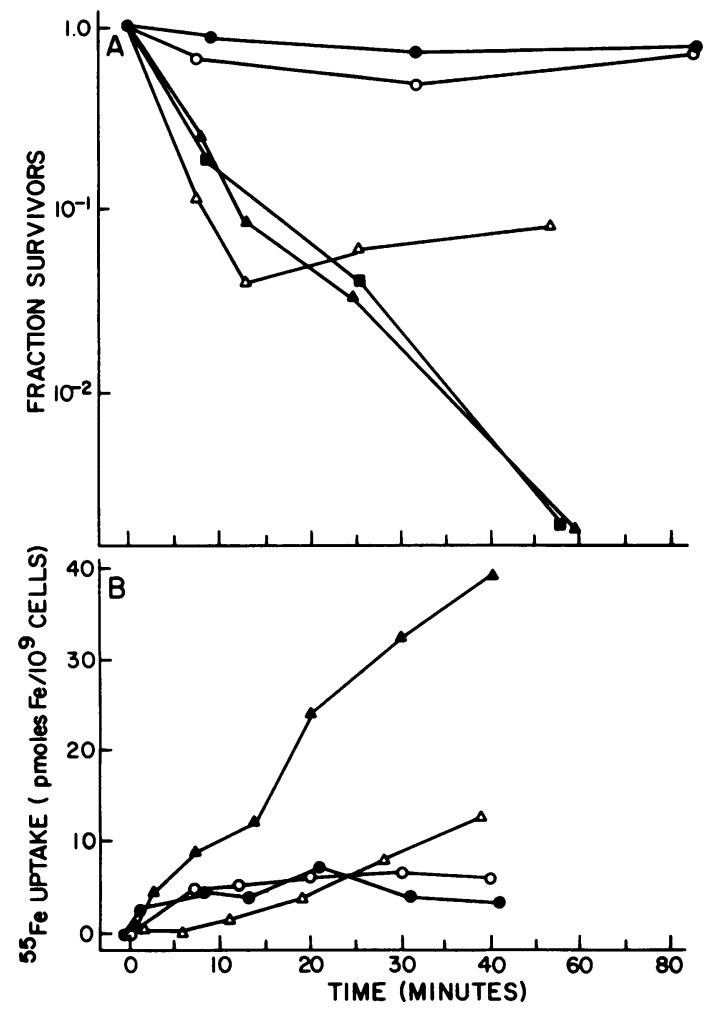

FIG. 4. Effect of citrate on (A) action of streptonigrin on and (B) uptake of ${ }^{55} \mathrm{Fe}^{3+}$ by strain AN102 (fep) grown overnight with and without citrate. (A) A sample of bacteria grown overnight in citrate $\left(10^{-2} \mathrm{M}\right)$ was grown to an optical density at $578 \mathrm{~nm}$ of 0.6 in citrate. The cells were spun down, washed as described in the text, and resuspended in M9 medium containing $2 \times$ $10^{-6} \mathrm{M} \mathrm{Fe}^{3+}$ plus requirements to an optical density at $578 \mathrm{~nm}$ of 0.6 . Concentrations of agents added at $0 \mathrm{~min}$ were: streptonigrin, $4 \times 10^{-5} \mathrm{M}$; citrate, $10^{-2} \mathrm{M}$; and NTA, $1.5 \times 10^{-4}$ M. Symbols: $\Delta$, streptonigrin; $\Delta$, streptonigrin plus citrate; $\mathbf{D}$, streptonigrin plus citrate plus NTA. Agents (at the same concentrations) were added at $\mathbf{0}$ min to log-phase cultures grown without citrate, as described in the text. Symbols: $\bigcirc$, streptonigrin; $O$, streptonigrin .plus citrate. (B) Log-phase cultures of strain AN102 were harvested, washed, and added to ${ }^{55} \mathrm{Fe}^{3+}$ uptake medium containing NTA $(1.5$ $\left.\times 10^{-4} \mathrm{M}\right)$ as described in the text. Cells grown without citrate: $(O)$ no addition to uptake medium, $(O)$ citrate $\left(10^{-2} \mathrm{M}\right)$ added to uptake medium. Cells grown overnight in citrate $\left(10^{-2} \mathrm{M}\right):(\Delta)$ no addition to uptake medium, $(\Delta)$ citrate $\left(10^{-2} \mathrm{M}\right)$ added to uptake medium.

which citrate-induced iron transport does occur, resulting in enhancement of streptonigrin killing in the presence of citrate.

\section{DISCUSSION}

Our studies have shown a correlation between the magnitude of killing by streptonigrin and the level of iron in the $E$. coli strains under investigation. Mutants defective in enterochelin biosynthesis have been used to show the requirement for iron in the bactericidal action of streptonigrin. At low iron levels, resulting from growth of the iron transport mutants in irondepleted medium, the cells were not readily killed by streptonigrin. When iron was made available in the cells, e.g., by addition of enterochelin to strains AB2847 and AN193, thereby initiating the ferrienterochelin transport system, the bactericidal action of streptonigrin was sharply increased. We have regulated the levels of iron in these mutants by addition of various precursors of enterochelin biosynthesis, enabling these strains to synthesize enterochelin and hence transport iron into the cells. The amount of transported iron has been measured by ${ }^{55} \mathrm{Fe}$ uptake studies, and viability studies with streptonigrin under similar conditions of iron uptake have been carried out to show that the lethality of streptonigrin increases with an increase of iron uptake by the cells.

In the $\operatorname{aroB}$ mutant strain $\mathrm{AB} 2847$, addition of either DHB or shikimate enables it to bypass the mutation and synthesize enterochelin. Iron uptake studies showed the expected increase in ${ }^{55} \mathrm{Fe}$ uptake upon addition of either of these precursors. An enhancement of killing by streptonigrin upon addition of DHB and shikimate under similar conditions was observed; a clear relationship exists between the level of iron uptake and the degree of streptonigrin killing in this strain. When enterochelin was added to strain $\mathrm{AB} 2847$, uptake of ${ }^{55} \mathrm{Fe}$ by the cells increased even more than upon addition of the precursors; correspondingly, viability studies showed that streptonigrin was more lethal to strain AB2847 in the presence of enterochelin than upon addition of DHB or shikimate. This is to be expected, as the addition of enterochelin enables the cells to take up iron immediately as a ferrienterochelin complex. This complex is then enzymatically degraded within the cell to release the iron that streptonigrin requires for its bactericidal action.

Iron uptake studies showed the expected increase of ${ }^{55} \mathrm{Fe}$ uptake by strain AN193 upon addition of the enterochelin precursor DHB. Viability studies showed a corresponding increase of streptonigrin killing with added DHB. As observed with strain AB2847, enterochelin caused a sharp increase in ${ }^{55} \mathrm{Fe}$ uptake by strain AN193, and the killing by streptonigrin was correspondingly enhanced upon addition of enterochelin.

Some comment should be made on the contrast between the abilities of the chelating agents orthophenanthroline and desferrioxamine to protect strain AB2847 from streptonigrin in the 
presence of enterochelin. Enterochelin is one of the most powerful $\mathrm{Fe}^{3+}$ chelators known $\left(K_{f}=\right.$ $\left.10^{52}\right)$, and desferrioxamine $\left(K_{f}=10^{30.6}\right)(15)$ is unable to prevent transport of iron into the cell via the ferrienterochelin complex. Subsequent killing by streptonigrin was therefore observed. Orthophenanthroline is a weaker chelator of $\mathrm{Fe}^{3+}\left(K_{f}=10^{14}\right)$ than the specific iron chelator desferrioxamine and did not interfere with the enhanced ${ }^{55} \mathrm{Fe}$ uptake observed in the presence of enterochelin. However, it did protect the cells from being killed by streptonigrin in the presence of enterochelin. An explanation for this may be that orthophenanthroline, observed to slow the growth of $E$. coli at $10^{-4} \mathrm{M}$ (unpublished data), could pass across the permeability barrier and enter the cells. It would then be available to chelate the intracellular iron, required by streptonigrin for its bactericidal action, that is either already present or being enzymatically released from the ferrienterochelin complex.

The experiments discussed above, on the response of siderophore mutants to enterochelin or its precursors and the effect of chelating agents, provide clear evidence that iron plays a special role in the action of streptonigrin. We now turn to the experimental evidence concerning the effect of citrate on streptonigrin lethality. These experiments also suggest a role for iron, as we pointed out in a previous paper (19), but there are some unresolved questions concerning the mechanism of the citrate effect.

We have used citrate, known to induce an iron transport system in strains of $E$. coli K-12 (4), as a tool for regulating levels of intracellular iron in strain AN102. In this strain, an iron transport system, in conjunction with new protein synthesis (9), is induced by overnight growth in citrate (3). Iron uptake studies showed an increased ${ }^{55} \mathrm{Fe}$ uptake in the presence of citrate. An increase in streptonigrin killing under similar conditions of iron uptake was observed. As shown in the enterochelin-promoted iron uptake experiments on strains AB2847 and AN193, the level of iron in the citrate-promoted iron uptake by strain AN102 corresponded to the degree of streptonigrin killing.

Iron uptake studies with strain AN193 showed an increase in ${ }^{55} \mathrm{Fe}$ uptake and a corresponding enhancement of killing by streptonigrin after about 20 min of growth in citrate. This lag time was eliminated by prior growth in citrate. Although these results suggest the presence of a citrate-promoted iron uptake system in this K-12 strain, experiments with chloramphenicol indicate that the effect of citrate may be more complex than solely to induce an iron transport system. Preincubation with chloramphenicol decreased but did not eliminate either the citrate enhancement of streptonigrin lethality or ${ }^{55} \mathrm{Fe}$ uptake. The inhibition of protein synthesis itself has been shown to enhance killing by streptonigrin (17), but this is not quite sufficient to account for the degree of killing observed with streptonigrin and citrate in the presence of chloramphenicol. The mode of citrate action on strain AN193, therefore, may involve more than citrate-induced iron transport into the cell. It may involve an indirect process, in which association of the complex with the cell membrane triggers the intracellular release of iron. This indirect process has been demonstrated (10) in the growth of avirulent $E$. coli in siderophore-containing serum.

Although the exact mechanism of the citrate effect on strain AN193 is not completely clear, experiments with desferrioxamine, a specific iron chelator, show that it is directly iron related. This relationship is shown by the ability of desferrioxamine to eliminate the effect of citrate $\left(K_{f}=10^{12}\right)$ on both promoting killing of strain AN193 by streptonigrin and increasing ${ }^{55} \mathrm{Fe}^{3+}$ uptake by the cells. Orthophenanthroline, like desferrioxamine, protects strain AN193 from being killed by streptonigrin in the presence of citrate. This may be explained by the fact that orthophenanthroline is a stronger iron chelator than citrate, in addition to the proposal that it may be available to chelate intracellular iron.

It now seems clear that iron, streptonigrin, and oxygen somehow interact to bring about DNA strand scission. Although details of the mechanism are unclear, we draw attention to the following facts. (i) Iron catalyzes the production of hydroxyl radicals from superoxide and hydrogen peroxide (8), both of which result from the autoxidation of streptonigrin. (ii) The binding of certain divalent heavy metal ion-streptonigrin complexes to DNA has been shown spectrophotometrically (17), and a similar ferrous ironstreptonigrin-DNA complex probably exists. Such a complex would assure that the formation of hydroxyl radicals or other active oxygen species would occur at the site of greatest effectiveness. (iii) The existence of a ferrous ironstreptonigrin complex has been demonstrated spectrophotometrically (17), but a complex between ferric iron and streptonigrin was not detected (19). This suggests the interesting possibility that, as the iron atom oscillates between the ferrous and ferric forms, it is alternately bound and released by streptonigrin.

\section{ACKNOWLEDGMENTS}

This research was supported by Public Health Service grant AI-14962 from the National Institute of Allergy and Infectious Diseases and by a University Research Council Grant from the University of North Carolina.

\section{LITERATURE CITED}

1. Bachmann, B. J., and K. B. Low. 1980. Linkage map of Escherichia coli K-12. Microbiol. Rev. 44:1-56.

2. Cone, R., S. K. Hasan, J. W. Lown, and A. R. Morgan. 
1976. The mechanism of the degradation of DNA by streptonigrin. Can. J. Biochem. 54:219-223.

3. Cox, G. B., F. Gibson, R. K. J. Luke, N. A. Newton, I. G. O'Brien, and H. Rosenberg. 1970. Mutations affecting iron transport in Escherichia coli. J. Bacteriol. 104:219-226.

4. Frost, G. E., and H. Rosenberg. 1973. The inducible citrate-dependent iron transport system in Escherichia coli K-12. Biochim. Biophys. Acta 330:90-101.

5. Harley, J. B., C. J. Fetterolf, C. A. Bello, and J. G. Flaks. 1982. Streptonigrin toxicity in Escherichia coli: oxygen dependence and the role of the intracellular oxidationreduction state. Can. J. Microbiol. 28:545-552.

6. Hassan, H. M., and I. Fridovich. 1977. Enzymatic defenses against the toxicity of oxygen and of streptonigrin in Escherichia coli. J. Bacteriol. 129:1574-1583.

7. Langman, L., I. G. Young, G. E. Frost, H. Rosenberg, and F. Gibson. 1972. Enterochelin system of iron transport in Escherichia coli: mutations affecting ferric-enterochelin esterase. J. Bacteriol. 112:1142-1149.

8. McCord, J. M., and E. D. Day, Jr. 1978. Superoxidedependent production of hydroxyl radical catalyzed by iron-EDTA complex. FEBS Lett. 86:139-142.

9. McIntosh, M. A., and C. F. Earhart. 1977. Coordinate regulation by iron of the synthesis of phenolate compounds and three outer membrane proteins in Escherichia coli. J. Bacteriol. 131:331-339.

10. Mellencamp, M. W., M. A. McCabe, and I. Kochan. 1981 The growth-promoting effect of bacterial iron for serumexposed bacteria. Immunology 43:483-491.

11. Miller, J. H. 1972. Experiments in molecular genetics, p.
431. Cold Spring Harbor Laboratory, Cold Spring Harbor, N.Y.

12. Pugaley, A. P., and P. Reeves. 1977. Uptake of ferrienterochelin by Escherichia coli: energy-dependent stage of uptake. J. Bacteriol. 130:26-36.

13. Rosen, H., and S. J. Klebanofr. 1981. Role of iron and ethylenediaminetetraacetic acid in the bactericidal activity of a superoxide anion-generating system. Arch. Biochem. Biophys. 208:512-519.

14. Rosenberg, H., and I. G. Young. 1974. Iron transport in the enteric bacteria, p. 67-82. In J. B. Neilands (ed.) Microbial iron metabolism. Academic Press, Inc., New York.

15. Sillen, L. G., and A. E. Martell. 1964. Stability constants of metal-ion complexes. The Chemical Society, London.

16. Wagesg, W., and V. Braun. 1981. Ferric citrate transport in Escherichia coli requires outer membrane receptor protein FecA. J. Bacteriol. 145:156-163.

17. White, H. L., and J. R. White. 1968. Lethal action and metabolic effects of streptonigrin on Escherichia coli. Mol. Pharmacol. 4:549-565.

18. White, J. R. 1977. Streptonigrin-transition metal complexes: binding to DNA and biological activity. Biochem. Biophys. Res. Commun. 77:387-391.

19. White, J. R., and H. N. Yeowell. 1982. Iron enhances the bactericidal action of streptonigrin. Biochem. Biophys. Res. Commun. 106:407-411.

20. Young, I. G., G. B. Cox, and F. Gibson. 1967. 2,3-Dihydroxybenzoate as a bacterial growth factor and its route of biosynthesis. Biochim. Biophys. Acta 141:319-331. 